\title{
Predictors of institutional delivery service utilization among women of reproductive age in Senegal: a population-based study
}

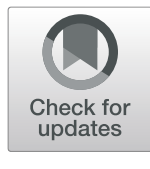

Betregiorgis Zegeye ${ }^{1}$, Bright Opoku Ahinkorah², Dina Idriss-Wheelr ${ }^{3}$, Olanrewaju Oladimeji ${ }^{4,5,6}$,

Comfort Z. Olorunsaiye ${ }^{7}$ and Sanni Yaya ${ }^{8,9^{*}}$ (1)

\begin{abstract}
Background: In Senegal, sub-Saharan Africa, many women continue to die from pregnancy and childbirth complications. Even though health facility delivery is a key intervention to reducing maternal death, utilization is low. There is a dearth of evidence on determinants of health facility delivery in Senegal. Therefore, this study investigated the predictors of health facility-based delivery utilization in Senegal.
\end{abstract}

Methods: Data from the 2017 Senegal Continuous Survey were extracted for this study, and approximately 11,487 ever-married women aged 15-49 years participated. Chi-square test was used to select significant variables and multivariable logistic regression analysis was performed to identify statistically significant predictors at a $95 \%$ confidence interval with a 0.05 p-value using Stata version 14 software.

Results: Facility-based delivery utilization was $77.7 \%$ and the main predictors were maternal educational status (primary school Adjusted Odds Ratio $[\mathrm{aOR}]=1.44,95 \% \mathrm{Cl}$; 1.14-1.83; secondary school aOR $=1.62,95 \% \mathrm{Cl}$; $1.17-$ 2.25), husband's educational status (primary school aOR $=1.65,95 \% \mathrm{Cl} ; 1.24-2.20$, secondary school aOR $=2.17,95 \%$ $\mathrm{Cl} ; 1.52-3.10$ ), maternal occupation (agricultural-self-employed $\mathrm{aOR}=0.77,95 \% \mathrm{Cl} ; 0.62-0.96$ ), ethnicity (Poular $\mathrm{aOR}=0.74,95 \% \mathrm{Cl} ; 0.56-0.97$ ), place of residence (rural $\mathrm{aOR}=0.57,95 \% \mathrm{Cl} ; 0.43,0.74$ ), media exposure (yes aOR $=$ $1.26,95 \% \mathrm{Cl} ; 1.02-1.57$ ), economic status (richest $\mathrm{aOR}=5.27,95 \% \mathrm{Cl} ; 2.85-9.73$ ), parity (seven and above $\mathrm{aOR}=0.46$, $95 \% \mathrm{Cl} ; 0.34-0.62$ ), wife beating attitude (refuse $\mathrm{aOR}=1.23,95 \% \mathrm{Cl} ; 1.05-1.44$ ) and skilled antenatal care (ANC) (yes $\mathrm{aOR}=4.34,95 \% \mathrm{Cl} ; 3.10-6.08)$.

\footnotetext{
*Correspondence: sanni.yaya@uOttawa.ca

${ }^{8}$ Faculty of Social Sciences, School of International Development and Global

Studies, University of Ottawa, 120 University Private, Ottawa, ON K1N 6N5,

Canada

${ }^{9}$ The George Institute for Global Health, Imperial College London, London, UK

Full list of author information is available at the end of the article
}

(c) The Author(s). 2021 Open Access This article is licensed under a Creative Commons Attribution 4.0 International License, which permits use, sharing, adaptation, distribution and reproduction in any medium or format, as long as you give appropriate credit to the original author(s) and the source, provide a link to the Creative Commons licence, and indicate if changes were made. The images or other third party material in this article are included in the article's Creative Commons licence, unless indicated otherwise in a credit line to the material. If material is not included in the article's Creative Commons licence and your intended use is not permitted by statutory regulation or exceeds the permitted use, you will need to obtain permission directly from the copyright holder. To view a copy of this licence, visit http://creativecommons.org/licenses/by/4.0/ The Creative Commons Public Domain Dedication waiver (http://creativecommons.org/publicdomain/zero/1.0/) applies to the data made available in this article, unless otherwise stated in a credit line to the data. 


\begin{abstract}
(Continued from previous page)
Conclusion: Uptake of health facility delivery services was seen among women who were educated, exposed to media, wealthy, against wife-beating, attended ANC by skilled attendants and had educated husbands. On the other hand, women from ethnic groups like Poular, those working in agricultural activities, living in rural setting, and those who had more delivery history were less likely to deliver at a health facility. Therefore, there is the need to empower women by encouraging them to use skilled ANC services in order for them to gain the requisite knowledge they need to enhance their utilization of health facility delivery, whiles at the same time, removing socio-economic barriers to access to health facility delivery that occur from low education, poverty and rural dwelling.
\end{abstract}

Keywords: Institutional delivery, Women, Reproductive age, Senegal, Maternal health, Global health, Sub-Saharan Africa

\section{Background}

Although significant progress has been made in the last two decades, worldwide, approximately 295, 000 women died from pregnancy and childbirth in 2017, which is unacceptably high [1]. Eighty-six percent of global maternal deaths occur in sub-Saharan Africa and Southern Asia [2]. However, there is evidence that in most countries where over $80 \%$ of deliveries are attended by health professionals, the Maternal Mortality Rate (MMR) is below 200 per 100,000 live births. In 2017, sub-Saharan Africa alone accounted for roughly two-thirds $(196,000)$ of maternal deaths, while Southern Asia accounted for nearly one-fifth $(58,000)$ [3].

Evidence shows that in low resourced countries in Africa, including Senegal, the cause of maternal death is often linked to non-use of health facility during delivery (also called institutional delivery) [4, 5]. Additional factors include poor socioeconomic status, inadequate access to health facility delivery, ineffective referral systems for women in obstetric emergencies, as well as long distance to health facilities among women who dwell in rural areas [6-8].

The Safe Motherhood Initiative considers institutional delivery as a crucial element in its emphasis on ensuring the availability and accessibility of skilled care during pregnancy and childbirth [9]. Utilization of institutional delivery has been considered as one of the most essential interventions to reduce maternal death, with the proportion of women who utilize skilled assistance during delivery regarded as a key indicator in every country's health plan [10-13]. A woman who gives birth at a health facility can receive sufficient medical care during childbirth, which helps to reduce preventable maternal and neonatal deaths [13-15].

In $2018,81 \%$ of the mothers delivered by skilled birth attendants globally; the percentages were $77 \%$ and $60 \%$ in Southern Asia and sub-Saharan Africa, respectively [2]. Beyond this, large disparities in uptake of skilled birth attendant services are seen. Globally, women in the richest subgroups are nearly twice as likely to be delivered by skilled birth attendants compared to the poorest women (91\% vs 51\%). Similarly, in sub-Saharan Africa, women in the richest subgroups are 2.4 times more likely to be delivered by skilled birth attendants than the poorest ( $88 \%$ vs $37 \%$ ) [2]. In Senegal, where the MMR is still very high (315/100,000 live births in 2017), some improvements have been made to increase access to health facility delivery from $41.4 \%$ in 1986 to $68.4 \%$ in 2017 [16].

Prior studies have reported barriers to using skilled delivery services that included behavioral, cultural, and economic factors as well as issues of inaccessibility to health facility, insufficient infrastructure and limited skilled human resources for healthcare at the community level [17-22]. Numerous scholars have also described the rationale behind non-utilization of health facility delivery in developing countries [17, 2226], and few studies have been conducted in Senegal related to facility delivery. However, it focused merely on coverage of health facility delivery $[27,28]$, one [29] or few [4] factors, restricted to one region [29, 30] and used old data (1997 \& 2014) [4] (2011) [29].

Recognition of drivers of utilization of the facilitybased delivery is a crucial step in reducing maternal and neonatal deaths. It can contribute to the development of interventions and policy changes for key populations to improve health outcomes for women and children, particularly in the context of high MMR in low-and middleincome countries [31]. The aim of this study was to examine the drivers of health facility-based delivery in Senegal using recent data from the 2017 Senegal Continuous Survey.

\section{Methods}

\section{Study setting}

Senegal, located in West Africa, is well-known as the "Entry to Africa" [32, 33]. Up to half of its 15.4 million people (as of 2016) live in and around Dakar and other urban areas [33]. Since 1960, three very non-violent political changes have taken place, 
ensuring its stability [34]. The nation's economic growth, reported at 6\% growth rate in 2018, looks promising for the future [34]. According to available data in 2011 by the World Bank, 38\% of Senegal's population lives on less than $\$ 1.90$ per day [34].

Senegal's health system is a hierarchical structure, with each of the 14 regional medical offices in charge of the provision and supervision of healthcare within the regions. There are also health districts which usually consist of one health center linked to rural health posts, some of which supervise the allied health huts [35]. There are also community-level facilities known as health huts, usually operated by a community health worker employed by community health committees [36].

\section{Data source and sampling procedure}

We used the most recent (2017) Senegal Continuous Survey (SCS) for this analysis [37]. Sampling for the 2017 SCS was done using a stratified, two-stage cluster sampling design to provide estimates for essential population and health indicators for the country. Large geographic settings known as enumeration areas (EAs) were selected in the first stage through Probability Proportional to Size (PPS). The survey included a total of 8800 (4092 in urban areas and 4708 in rural) households and a total of 16,787 women (15-49 years of age) and 6977 Men (15-59 years of age) were interviewed [37]. Household listing was completed in each EA to ready the sampling frame. Selected participants were questioned using standard and country-specific questionnaire modules covering a wide range of health topics. For this study, we included 11,487 currently married women aged 15-49 years with a birth, for the most recent live births in the 5 years preceding the survey [37] from the kids (children) recode file (KR). The survey is publicly available on the DHS website (www.dhsprogram.com).

\section{Variables selection \\ Dependent variable}

Place of delivery was the outcome variable in this study and was grouped into health facility delivery (deliveries that occurred in a government hospital, government health center/maternity, government health post, mobile government clinic, government field worker, other public sector, private hospital/clinic and other private sectors) and non-health facility delivery (deliveries that occurred at respondents' or relatives' homes, or in other places like on the road). Births with missing information were added to the denominator for both the distribution of place of delivery and percentage of all births that occurred in a health facility. The percentage distribution of place of delivery included a separate category for missing values. Despite the fact that data were available for all live births to questioned women in the 5 years preceding the survey, we calculated for only the most recent birth as recommended by DHS guideline.

\section{Independent variables}

Several individual and community level explanatory variables were incorporated from previous studies $[17,21$, $23,24,38-43$ ] due to their role in contributing to increase or decrease in the use of facility delivery. The independent variables were maternal age (15-19, 20-24, 25-29, 30-34, 35-39, 40-44, 45-49), maternal educational status (no formal education, primary school, secondary school, higher), maternal occupation (not working, sales and services, agricultural-self-employed, other), husband education (no formal education, primary school, secondary school, higher), husband occupation (not working, professional/technical or managerial, sales and services, agricultural-self-employed, skilled manual, unskilled manual, other), religion (Muslim, Christian), ethnicity (Wolof, Poular, Serer, Mandingue/Soce, Diola, Soninke, other Senegalese, other), region (Dakar, Ziguinchor, Diourbel, Saint-Louis, Tambacounda, Kaolack, Thios, Louga, Fatick, Kolda, Matam, Kaffrine, Kedougou, Sedhiou), and wealth index (poorest, poorer, middle, richer, richest).

We looked at media exposure (if the respondent was exposed to any of the three types; read newspaper, listened to radio or watched television for at least less than once a week it was coded as yes, and otherwise, no), place of residence (urban, rural), and parity $(<=2,3-4$, $5-6,7+)$. Decision making power was also included; we looked to see if the respondent had no decision-making power, she alone made decisions, or if she made decisions together with her husband. There were three decision making parameters; decision making about her health, to purchase large household items, to visit family/relatives. We coded "no decision making" if only the husband or other family members made decisions; we coded "decision making one" if the respondent had decision making power either alone or together with her husband on two of the above decision-making parameters; and we coded "decision making power two" if the respondent made decisions alone or together with her husband on all three decision making power parameters. Attitude toward wife beating was assessed as "refused" if the respondent disagreed with all five of the wife beating circumstances presented (burning the food while cooking, arguing with husband, going to visit family without husband permission, neglecting children, refusing to have sex with her husband), and "accepted" if she agreed to any of the five wife beating parameters. We included the use of skilled antenatal care (ANC); if the women had ANC follow up by a skilled attendant (i.e. doctor, midwife, nurse) we coded as yes, if not we coded as no. 


\section{Data analysis}

The participants' socio-demographic characteristics were computed. Chi-square test was performed to identify variables that showed significant associations with the outcome variable at $p$-value less than 0.05 cut point. These variables were entered into the multivariable logistic regression model. Results of the multivariable logistic regression were reported using adjusted odds ratios (aORs) at a 95\% confidence interval. Data was analyzed using Stata version 14 software (Stata Corp, College Station, Texas, USA). Weighting was applied using the guidelines provided in the user manual (https://www.dhs program.com/pubs/pdf/DHSG4/Recode7_DHS_10Sep201 8_DHSG4.pdf), while the 'SVY' command was used to account for the complex sampling design.

\section{Ethical clearance}

Since we used secondary data from SCS dataset which is available publicly, we did not need further ethical approval to use the data. However, in addition to obtaining the participants consent prior to survey, the ICF international strictly followed the ethical standards collaborating with the concerned country's Ethical Review Board to ensure the DHS data collection process was in line with the U.S. Department of Health and Human Services regulations for the respect of the right of human subjects.

\section{Results}

In this study, a total of 11,487 married women were included, of whom 2926 (25.5\%) were 25-29 years old, and more than three-fifths $(67.5 \%)$ were rural residents (Table 1). More than two-thirds (67.2\%) of the participants and three fourth $(75.6 \%)$ of their partners had no formal education. Nearly two-fifth (38.9\%) of the respondents were unemployed, whereas more than one fourth $(28.3 \%)$ of them were self-employed in agriculture. The majority (97.7\%) of the participants were from the Muslim faith, and about $87.5 \%$ of the respondents were from Poular (33.3\%), Wolof (30.9\%), Serer (13.7\%) and Mandingue/Soc (10.1\%) ethnicities. Most of the participants (88.9\%) had exposure to media, at least once a week to newspaper, radio or television.

Regarding women empowerment, about 7716 (67.2\%) had no decision-making power about their own health, to purchase household expenses and to visit family/relatives. Only $2509(21.8 \%)$ and $1262(10.9 \%)$ of the participants had decision-making power on two and three of the above decision-making parameters, respectively. More than three-fifth (61.5\%) of the participants accepted wifebeating. The majority (96.1\%) of them attended ANC.

\section{Predictors of health facility delivery}

The coverage of health facility delivery among married women was $77.7 \%$. Several individual and community level factors were identified as predictors of health facility deliveries. Compared to women who had no formal education, health facility deliveries were higher by $44 \%(\mathrm{aOR}=1.44,95 \% \mathrm{CI} ; 1.14-1.83)$ and $62 \%(\mathrm{aOR}=$ 1.62 , 95\% CI; 1.17-2.25) among women who had primary and secondary school education respectively (Table 2).

Similarly, health facility delivery among women whose husbands had primary education were approximately $65 \%(\mathrm{aOR}=1.65,95 \% \mathrm{CI} ; 1.24-2.20)$ and secondary education were approximately 2.2 times $(\mathrm{aOR}=2.17,95 \%$ CI; 1.52-3.10) higher compared to women whose husbands had no formal education. Maternal occupation also had a significant association with health facility delivery with women who were self-employed in agriculture $23 \%(\mathrm{aOR}=0.77,95 \% \mathrm{CI} ; 0.62-0.96)$ less likely to deliver in health facilities compared to women who were not working.

In our study, health facility delivery among women from Poular ethnic groups was lower by $26 \%$ (aOR = 0.74, 95\% CI; 0.56-0.97) as compared to women from Wolof ethnic groups. With place of residence, health facility delivery among women living in a rural settings was lower by $43 \%(\mathrm{aOR}=0.57,95 \% \mathrm{CI} ; 0.43,0.74)$ as compared to urban resident women. Women who had exposure to newspaper, radio or television for at least less than once a week were $26 \%(\mathrm{aOR}=1.26,95 \% \mathrm{CI}$; 1.02-1.57) more likely than women with no media exposure to delivery in health facilities. Health facility delivery among women in the richer and richest households were 3.8 times $(\mathrm{aOR}=3.88$, 95\% CI; 2.545.91 ) and 5.2 times $(\mathrm{aOR}=5.27,95 \% \mathrm{CI} ; 2.85-9.73)$ higher than for women in the poorest households, respectively.

Compared to women who delivered two or less children, health facility delivery among women who delivered $3-4$ and $5-6$ or more children, was lower by $34 \%$ $(\mathrm{aOR}=0.66,95 \% \mathrm{CI} ; 0.54-0.79)$ and $47 \%(\mathrm{aOR}=0.53$, 95\% CI; 0.42-0.67), respectively. Similarly, health facility delivery among women who delivered seven or more children was lower by $54 \%(\mathrm{aOR}=0.46,95 \% \mathrm{CI}$; 0.34 0.62 ) as compared to women who delivered two or less children.

Health facility delivery among women who refused wife-beating for any reason was higher by $23 \%(\mathrm{aOR}=$ 1.23 , 95\% CI; $1.05-1.44)$ as compared to women who accepted wife-beating for any reason. Compared to married women who had not received skilled ANC followup, health facility delivery among married women who had skilled ANC follow-up was approximately 4.3 times $(\mathrm{aOR}=4.34,95 \% \mathrm{CI} ; 3.10-6.08)$ higher.

\section{Discussion}

Senegal has a high MMR and the utilization of institutional deliveries is low [16]. In this study, we used the 2017 SCS to assess predictors of health facility delivery 
Table 1 Respondents' socio-economic characteristics, 2017 Senegal Continuous Survey

\begin{tabular}{lll}
\hline Variable & Frequency & Percent \\
Health facility delivery & & \\
\hline No & & 22.33 \\
Yes & 3074 & 77.67
\end{tabular}

\section{Maternal age}

$15-19$
$20-24$
$25-29$
$30-34$
$35-39$
$40-44$
$45-49$

Maternal educational status

No formal education

Primary school

Secondary school

Higher

\section{Maternal occupation}

Not working
Sales and services
Agricultural-self employed
Others

\section{Husband educational status}

No formal education

Primary school

Secondary school

Higher

\section{Husband occupation}

Not working

Professional/technical or managerial

Sales and services

Agricultural-self employed

Skilled manual

Unskilled manual

Other

\section{Religion}

Muslim

Christian

\section{Ethnicity}

Wolof
Poular
Serer
Mandingue/ soce
Diola

$\begin{array}{lll}561 & 4.88 & 125(22.28) \\ 2202 & 19.17 & 526(23.89) \\ 2926 & 25.47 & 789(26.97) \\ 2733 & 23.79 & 733(26.82) \\ 1801 & 15.68 & 489(27.15) \\ 973 & 8.47 & 311(31.96) \\ 291 & 2.53 & 101(34.71)\end{array}$

7719

2320

1290

155

$\begin{array}{lll}4474 \mathrm{~s} & 38.95 & 2590(33.55) \\ 2422 & 21.08 & 363(15.65) \\ 3245 & 28.25 & 118(9.15) \\ 1346 & 11.72 & 1(0.65)\end{array}$

8688

1366

1025

408

290

1147

2015

3179

1606

1805

1445

11,224
263

3019 (26.90)

3556

3820

1575

1159

345
695 (19.54)

1291 (33.80)

331 (21.02)

442 (38.14)

$29(8.41)$
97.71

2.29

55 (20.91)

Not health facility

Frequency (\%)

$\begin{array}{ll}67.22 & 2590(33.55) \\ 20.20 & 363(15.65) \\ 11.23 & 118(9.15) \\ 1.35 & 1(0.65)\end{array}$

75.63

11.89

8.92

3.55

2.52

9.99

17.54

27.67

13.98

15.71

12.58

$2771(31.89)$
$192(14.06)$
$87(8.49)$
$24(5.88)$

24 (5.88)

74 (25.52)

144 (12.55)

448 (22.23)

$1372(43.16)$

309 (19.24)

383 (21.22)

$344(23.81)$

30.96

33.25

13.71

10.09

3.00 $x 2=38.03, p<0.001$

$436(77.72)$
$1676(76.11)$
$2137(73.03)$
$2000(73.18)$
$1312(72.85)$
$662(68.04)$
$190(65.29)$

$x 2=586.21, p<0.001$

$5129(66.45)$

1957 (84.35)

$1172(90.85)$

154 (99.35)

$X 2=586.21, p<0.001$

5129 (66.45)

1957 (84.35)

1172 (90.85)

154 (99.35)

$x 2=494.70, p<0.001$

5917 (68.11)

1174 (85.94)

938 (91.51)

384 (94.12)

$x 2=656.59, p<0.001$

216 (74.48)

1003 (87.45)

1567 (77.77)

1807 (56.84)

1297 (80.76)

1422 (78.78)

1101 (76.19)

$$
X 2=4.69, P=0.030
$$

8205 (73.10)

208 (79.09)

$$
x 2=369.60, p<0.001
$$

$2861(80.46)$

2529 (66.20)

1244 (78.98)

717 (61.86)

316 (91.59) 
Table 1 Respondents' socio-economic characteristics, 2017 Senegal Continuous Survey (Continued)

\begin{tabular}{|c|c|c|c|c|c|}
\hline \multirow{2}{*}{$\begin{array}{l}\text { Variable } \\
\text { Health facility delivery }\end{array}$} & \multirow[t]{2}{*}{ Frequency } & \multirow[t]{2}{*}{ Percent } & \multicolumn{2}{|l|}{ Place of delivery } & \multirow[t]{2}{*}{ Chi-square, $p$-values } \\
\hline & & & $\begin{array}{l}\text { Not health facility } \\
\text { Frequency (\%) }\end{array}$ & $\begin{array}{l}\text { Health facility, } \\
\text { Frequency (\%) }\end{array}$ & \\
\hline Soninke & 186 & 1.62 & $46(24.73)$ & $140(75.27)$ & \\
\hline Other Senegalese & 522 & 4.54 & $124(23.75)$ & $398(76.25)$ & \\
\hline Other & 324 & 2.82 & $116(35.80)$ & $208(64.20)$ & \\
\hline Region & & & & & $x^{2}=908.29, p<0.001$ \\
\hline Dakar & 677 & 5.89 & $30(4.43)$ & $647(95.57)$ & \\
\hline Ziguinchor & 497 & 4.33 & $56(11.27)$ & 441 (88.73) & \\
\hline Diourbel & 988 & 8.60 & $206(20.85)$ & $782(79.15)$ & \\
\hline Saint-Louis & 730 & 6.36 & $158(21.64)$ & $572(78.36)$ & \\
\hline Tambacounda & 920 & 8.01 & $436(47.39)$ & $484(52.61)$ & \\
\hline Kaolack & 719 & 6.26 & $151(21.00)$ & $568(79.00)$ & \\
\hline Thiès & 878 & 7.64 & $97(11.05)$ & 781 (88.95) & \\
\hline Louga & 835 & 7.27 & $196(23.47)$ & $639(76.53)$ & \\
\hline Fatick & 861 & 7.50 & $165(19.16)$ & $696(80.84)$ & \\
\hline Kolda & 864 & 7.52 & $297(34.38)$ & $567(65.63)$ & \\
\hline Matam & 886 & 7.71 & $261(29.46)$ & $625(70.54)$ & \\
\hline Kaffrine & 1111 & 9.67 & $357(32.13)$ & $754(67.87)$ & \\
\hline Kedougou & 658 & 5.73 & $333(50.61)$ & $325(49.39)$ & \\
\hline Sedhiou & 863 & 7.51 & $331(38.35)$ & $532(61.65)$ & \\
\hline Wealth index & & & & & $x 2=7.35, p<0.001$ \\
\hline Poorest & 3646 & 31.74 & $1727(47.37)$ & 1919 (52.63) & \\
\hline Poorer & 2898 & 25.23 & $859(29.64)$ & $2039(70.36)$ & \\
\hline Middle & 2483 & 21.62 & $361(14.54)$ & $2122(85.46)$ & \\
\hline Richer & 1477 & 12.86 & 87 (5.89) & $1390(94.11)$ & \\
\hline Richest & 983 & 8.56 & $40(4.07)$ & $943(95.93)$ & \\
\hline Media exposure & & & & & $x^{2}=474.47, p<0.001$ \\
\hline No & 1278 & 11.13 & $667(52.19)$ & $611(47.81)$ & \\
\hline Yes & 10,209 & 88.87 & $2407(23.58)$ & $7802(76.42)$ & \\
\hline Place of residence & & & & & $x^{2}=922.16, p<0.001$ \\
\hline Urban & 3737 & 32.53 & $325(8.70)$ & $3412(91.30)$ & \\
\hline Rural & 7750 & 67.47 & $2749(35.47)$ & $5001(64.53)$ & \\
\hline Parity & & & & & $x^{2}=429.70, p<0.001$ \\
\hline$<=2$ & 3612 & 31.44 & $585(16.20)$ & $3027(83.80)$ & \\
\hline $3-4$ & 3520 & 30.64 & $917(26.05)$ & $2603(73.95)$ & \\
\hline $5-6$ & 2396 & 20.86 & $786(32.80)$ & $1610(67.20)$ & \\
\hline $7+$ & 1959 & 17.05 & $786(40.12)$ & $1173(59.88)$ & \\
\hline Decision making & & & & & $x^{2}=105.23, p<0.001$ \\
\hline No decision making & 7716 & 67.17 & $2292(29.70)$ & $5424(70.30)$ & \\
\hline Decision making one & 2509 & 21.84 & $535(21.32)$ & $1974(78.68)$ & \\
\hline Decision making two & 1262 & 10.99 & $247(19.57)$ & $1015(80.43)$ & \\
\hline Wife beating attitude & & & & & $x^{2}=347.04, p<0.001$ \\
\hline Accept & 7062 & 61.48 & $2320(32.85)$ & $4742(67.15)$ & \\
\hline Refuse & 4425 & 38.52 & $754(17.04)$ & $3671(82.96)$ & \\
\hline
\end{tabular}


Table 1 Respondents' socio-economic characteristics, 2017 Senegal Continuous Survey (Continued)

\begin{tabular}{|c|c|c|c|c|c|}
\hline \multirow{2}{*}{$\begin{array}{l}\text { Variable } \\
\text { Health facility delivery }\end{array}$} & \multirow[t]{2}{*}{ Frequency } & \multirow[t]{2}{*}{ Percent } & \multicolumn{2}{|l|}{ Place of delivery } & \multirow[t]{2}{*}{ Chi-square, $p$-values } \\
\hline & & & $\begin{array}{l}\text { Not health facility } \\
\text { Frequency (\%) }\end{array}$ & $\begin{array}{l}\text { Health facility, } \\
\text { Frequency (\%) }\end{array}$ & \\
\hline Skilled ANC & & & & & $x 2=350.81, p<0.001$ \\
\hline No & 304 & 3.86 & $211(69.41)$ & $93(30.59)$ & \\
\hline Yes & 7578 & 96.14 & $1701(22.45)$ & $5877(77.55)$ & \\
\hline
\end{tabular}

among married women in Senegal. Similar to previous studies $[38,44]$, our findings indicate that the use of a health facility for delivery among educated mothers was better than that of mothers with no education. A possible reason could be that educated mothers are more likely to receive care during pregnancy and delivery than uneducated mothers [39]. In addition, educated mothers are believed to be informed on possible signs of obstetric danger, which allows them to seek prompt medical advice [45]. Again, there is an influence of education on women's healthcare-seeking behavior as it enhances health awareness of services and self-efficacy [38, 44]. Being married to educated husbands also positively predicted the use of health facility-based delivery in our study; previous studies suggest that educated husbands encourage wives to deliver in a health facility [23, 24, 40, 41]. Findings on the association between level of education and the use of health facility delivery indicates the need for government to provide access to education in the country, especially for the girl-child. Apart from the mainstream education in the classroom, media channels such as radio and television can be used as sources of information on the importance of health facility delivery for pregnant women.

We found an association between household wealth status and use of facility delivery and this suggests a doseresponse gradient. The odds of facility-based delivery increased as household wealth quintile increased. Findings from our study were similar with previous studies [38]. Reducing poverty or increasing household income generation may lead to improved access to facility-based delivery services [38]. Also, poor households may not be able to pay for cost of transportation in case of referral as distance to the health facility can also be a geographic barrier (i.e. the health facility is far from home [38]. Findings on the disparities in the use of health facility delivery, with poor women less likely to use health facility delivery compared to rich women, show a socio-economic gap that can be bridged by ensuring access to health facility delivery for all, irrespective of wealth status. This can be achieved by removing the financial barriers in access to health facility delivery in the country.

There was a positive association between use of skilled ANC and health facility delivery. This suggests that women who deliver in health facilities are more likely to have adequate knowledge about the risks associated with home delivery and consequences of complicated pregnancy, and understand the essence of delivering at health facilities $[46,47]$. It is possible that improving the coverage of skilled ANC services may increase the use of facility delivery [17]. Evidence shows that women who have skilled ANC attendance are more conscious of the risks related to childbirth and therefore have high propensity to deliver at healthcare institutions [48]. Similar findings were seen in Tanzania [42], Ghana [43], Nigeria [49] and Ethiopia [50, 51]. The birth preparedness plan is a key part of the first four ANC visits, a time during which pregnant mothers may be convinced to deliver at health institutions [51]. Study findings call for the need to empower women by encouraging them to use skilled ANC services for them to gain the requisite knowledge to enhance their utilization of health facility delivery.

Consistent with previous work $[17,51]$, this study confirmed that living in urban settings has a positive influence on institutional delivery. In low-and middle-income countries, mass media communication plays an essential role in enhancing knowledge and awareness about health issues among the general population leading to the promotion of the use of maternity services [17]. Specifically, women who are exposed to media might have a chance to become informed about institutional delivery services and the potential negative consequences of home delivery [51]. Hence, enhancing media exposure will help provide quality healthcare communication that can lead to an improvement in the uptake of health facility deliver services, as supported in a previous study [17].

In line with previous studies [25, 26, 51, 52], our study also showed lower utilization of facility delivery among women who live in rural settings. Women who live in urban settings often have more access to resources and better quality of health services $[17,22]$. As well, mothers who live close to health care institutions may be more likely to utilize ANC services, where they will have better access to health education, coupled with ease of transportation [51] and increased awareness of obstetric danger signs that are life-threating for mother and fetus [45]. Findings on the disparities in the use of health facility delivery in rural and urban areas show that the geographical gap can be bridged by ensuring access to health facility delivery for rural dwellers. 
Table 2 Predictors of health facility delivery in Senegal: Evidence from the 2017 Senegal Continuous Survey

\begin{tabular}{l} 
Variables \\
\hline Maternal age \\
$15-19$ \\
$20-24$ \\
$25-29$ \\
$30-34$ \\
$35-39$ \\
$40-44$ \\
$45-49$
\end{tabular}

Maternal educational status

No formal education

Primary school

Secondary school

Higher

\section{Maternal occupation}

Not working

Sales and services

Agricultural-self employed

Others

\section{Husband educational status}

No formal education

Primary school

Secondary school

Higher

\section{Husband occupation}

Not working

Professional/technical or managerial

Sales and services

Agricultural-self employed

Skilled manual

Unskilled manual

Other

\section{Religion}

Muslim

Christian

Ethnicity

Wolof

Poular

Serer

Mandingue/ soce

Diola

Soninke

Other senegalese

Other

aOR $(95 \% \mathrm{Cl})$

1.00

$0.81(0.57-1.15)$

$0.73(0.49-1.08)$

$0.95(0.64-1.42)$

$1.11(0.70-1.74)$

$0.86(0.54-1.38)$

$1.01(0.55-1.86)$

1.00

$1.44(1.14-1.83)^{* *}$

$1.62(1.17-2.25)^{* *}$

$21.20(2.70-166.32)^{* *}$

1.00

$0.97(0.78-1.21)$

$0.77(0.62-0.96)^{*}$

$0.88(0.66-1.17)$

1.00

$1.65(1.24-2.20)^{* *}$

$2.17(1.52-3.10)^{* * *}$

$1.49(0.65-3.43)$

1.00

$0.71(0.41-1.24)$

$0.96(0.59-1.57)$

$0.92(0.57-1.47)$

$1.28(0.76-2.14)$

$1.06(0.66-1.73)$

$0.98(0.61-1.56)$

1.00

$1.24(0.66-2.34)$

1.00

$0.74(0.56-0.97)^{*}$

$0.96(0.68-1.36)$

$0.86(0.57-1.27)$

$0.93(0.47-1.84)$

$0.90(0.42-1.92)$

$0.82(0.50-1.32)$

$0.59(0.37-0.93)^{*}$
Table 2 Predictors of health facility delivery in Senegal: Evidence from the 2017 Senegal Continuous Survey (Continued)

\begin{tabular}{ll}
\hline Variables & aOR (95\% Cl) \\
\hline Region & 1.00 \\
Dakar & $1.24(0.51-2.99)$ \\
Ziguinchor & $0.91(0.46-1.78)$ \\
Diourbel & $1.01(0.48-2.10)$ \\
Saint-Louis & $0.67(0.32-1.40)$ \\
Tambacounda & $1.10(0.48-2.55)$ \\
Kaolack & $1.29(0.66-2.53)$ \\
Thies & $0.85(0.41-1.77)$ \\
Louga & $1.40(0.71-2.75)$ \\
Fatick & $1.26(0.58-2.70)$ \\
Kolda & $0.97(0.43-2.16)$ \\
Matam & $1.51(0.71-3.22)$ \\
Kaffrine & $0.45(0.19-1.06)$ \\
Kedougou & $0.71(0.33-1.50)$ \\
Sedhiou & \\
Place of residence & 1.00 \\
Urban & $0.57(0.43-0.74)^{* * *}$ \\
Rural &
\end{tabular}

\section{Media exposure}

No

1.00

Yes

$1.26(1.02-1.57)^{*}$

Wealth index

Poorest

1.00

Poorer

$1.98(1.61-2.43)^{* * *}$

Middle

$2.92(2.12-4.03)^{* * *}$

Richer

Richest

$3.88(2.54-5.91)^{* * *}$

$5.27(2.85-9.73)^{* * *}$

\section{Parity}

$0-2 \quad 1.00$

$3-4$

5-6

$7+$

$0.66(0.54-0.79)^{* * *}$

$0.53(0.42-0.67)^{* * *}$

$0.46(0.34-0.62)^{* * *}$

Decision making

No decision making

1.00

Decision making one

$1.07(0.86-1.33)$

Decision making two

$0.98(0.73-1.30)$

Wife beating attitude

$\begin{array}{ll}\text { Accept } & 1.00\end{array}$

Refuse $1.23(1.05-1.44)^{* *}$

Skilled ANC

No $\quad 1.00$

Yes $4.34(3.10-6.08)^{* * *}$ 
This study showed that women working in an agricultural setting are disadvantaged when it comes to delivery at health facilities compared with non-working women, as reported in a prior study [17]. This has been attributed to the monetary and livelihood suffering that occur in the lives of women engaged in agriculture [17]. Another possible reason could be that such women may prioritize and give particular focus to farming communities compared to utilization of maternal healthcare promotion programs.

We found disparities in utilization of facility delivery across ethnic groups with women of the Poular ethnic groups less likely to use health facility delivery services compared to those of the Wolof ethnic group. Possible explanations for the disparities across ethnic groups could be the health insurance use, attitudes of physicians towards minority people, language barriers, transportation cost, low level of education, literacy, poverty and low socio-economic status, familiarity with the health care delivery system, the degree and kind of family support as well as belonging to a lower group in the ethnic hierarchy [53-57].

Consistent with a previous study in Tanzania [58], our study further suggests a strong association between parity and health facility delivery; a mother with more delivery history was less likely to use facility delivery. One possible reason could be that mothers with previous positive birth outcomes from home delivery may choose to deliver again in the home. The other explanation could be, if they had experienced poor quality care, including disrespect by health professionals in a previous facility delivery, they may not want to have another facility delivery.

Our study found decreased likelihood of facility delivery utilization among women who accepted wife-beating as a usual or healthy part of living. Evidence shows women who experience beating are less likely to use health services such as ANC [59], which, may decrease their facility delivery utilization. A possible explanation could be that women may experience beating by the husband when they go to a facility without his permission [60].

A key strength of this study was the use of recent nationally representative data that allows investigation of current barriers for institutional delivery, and in turn, help propose timely interventions to work towards achievement of the Sustainable Development Goal (SDGs). Nevertheless, there are several limitations that should be acknowledged. First, the use of cross-sectional data implies that the authors cannot indicate causality but rather associations with the findings. Again, there is also the likelihood of recall and reporting bias since the data were self-reported. The factors that predict facility delivery are varied and multidimensional, but the choice of the independent variables was limited to those available in the dataset.

\section{Conclusion}

Using the recent 2017 SCS, both the coverage of facility delivery and its individual and community level predictors were comprehensively assessed. Better uptake of facility delivery service was seen among women who were educated, exposed to media, richer or richest, against wife-beating, attended ANC by skilled attendants and had educated husbands. On the other hand, women from some ethnic groups like Poular, those working in agricultural activities, living in rural settings, and those with more history of delivery were less likely to have health facility delivery. Therefore, there is the need to empower women by encouraging them to use skilled ANC services in order for them to gain the requisite knowledge to enhance their utilization of health facility delivery, while at the same time, removing socioeconomic barriers to access to health facility delivery that occur from low education, poverty and rural dwelling.

\section{Abbreviations \\ AOR: Adjusted Odd Ratio; DHS: Demographic and Health Survey; EA: Enumeration Area; ICF: Inner City Fund; IR: Individual Recode; IRB: Institutional Review Board; PPS: Probability Proportional to Size; SCS: Senegal Continuous Survey; SDG: Sustainable Development Goal; WHO: World Health Organization}

\section{Acknowledgments}

We acknowledge the Demographic and Health Surveys Program for making the DHS data available, and we thank the women who participated in the surveys.

Authors' contributions

SY and BZ contributed to the conception and design of the study, interpreted the data, prepared the manuscript, and led the paper. BOA, DIW, $\mathrm{OO}$ and CZO helped with data analysis, provided technical support in interpretation of results and critically reviewed the manuscript for its intellectual content. SY had final responsibility to submit. All authors read and revised drafts of the paper and approved the final version.

\section{Funding}

No funding was received for this work.

\section{Availability of data and materials}

The datasets generated and/or analyzed during the current study are available in http://dhsprogram.com/data/available-datasets.cfm.

\section{Ethics approval and consent to participate}

Ethics approval was not required since the data is available to the public domain.

\section{Consent for publication}

Not applicable.

\section{Competing interests}

The authors declare no competing interests.

\section{Author details}

${ }^{1}$ HaSET Maternal and Child Health Research Program, Shewarobit Field Office, Shewarobit, Ethiopia. ${ }^{2}$ The Australian Centre for Public and Population Health Research (ACPPHR), Faculty of Health, University of Technology Sydney, 
Sydney, Australia. Interdisciplinary School of Health Sciences, University of Ottawa, Ottawa, Ontario, Canada. ${ }^{4}$ Department of Public Health, Walter Sisulu University, Mthatha, Eastern Cape, South Africa. ${ }^{5}$ Faculty of Health Sciences, Durban University of Technology, Durban, South Africa. ${ }^{6}$ Department of Family Medicine and Public Health, Faculty of Medicine, University of Botswana, Gaborone, Botswana. 'Department of Public Health, Arcadia University, Glenside, PA, USA. ${ }^{8}$ Faculty of Social Sciences, School of International Development and Global Studies, University of Ottawa, 120 University Private, Ottawa, ON K1N 6N5, Canada. 'The George Institute for Global Health, Imperial College London, London, UK.

\section{Received: 22 September 2020 Accepted: 15 December 2020} Published online: 11 January 2021

\section{References}

1. Cunningham K, Martinez DA, Scott-Sheldon LA, Carey KB, Carey MPJJoc, abuse as. Alcohol use and sexual risk behaviors among adolescents with psychiatric disorders: A systematic review and meta-analysis. J Child Adolesc Subst Abuse. 2017;26(5):353-66.

2. UNICEF. Delivery care 2020. [Available from: <https://data.unicef.org/topic/ maternal-health/delivery-care/>]. [cited 31 May 2020].

3. World Health Organization (WHO). Maternal mortality. [Available from: <http://www.who.int/mediacentre/factsheets/fs348/en/>. Accessed on 06 May 2020].

4. Doctor HV, Nkhana-Salimu S, Abdulsalam-Anibilowo M. Health facility delivery in sub-Saharan Africa: successes, challenges, and implications for the 2030 development agenda. BMC Public Health. 2018;18(1):765.

5. Adedokun ST, Uthman OA. Women who have not utilized health Service for Delivery in Nigeria: who are they and where do they live? BMC Pregnancy Childbirth. 2019;19(1):93.

6. Maternal mortality fact sheet no 384. Geneva: WHO; 2015. [Available on http://www.who.int/mediacentre/factsheets/fs348/en/index.htm. Accessed on 06 May 2020].

7. World Health Organization. Trends in maternal mortality: 1990 to 2015 estimates by WHO, UNICEF, UNFPA, World Bank Group and the United Nations population division. Geneva: WHO; 2015

8. MacDonald ME, Diallo GS. Socio-cultural contextual factors that contribute to the uptake of a mobile health intervention to enhance maternal health care in rural Senegal. Reprod Health. 2019;16:141.

9. Central Statistical Authority (CSA) [Ethiopia], and ORC Macro. Ethiopia Demographic and Health Survey 2000. Addis Ababa, Ethiopia and Calverton: CSA and ORC Macro; 2001.

10. Khan KS, Wojdyla D, Say L, Gülmezoglu AM, Van Look PF. WHO analysis of causes of maternal death: a systematic review. Lancet. 2006:367(9516):1066-74.

11. Group SMI-A. The safe motherhood action agenda: priorities for the next decade, report on the safe motherhood technical consultation 18-23 October 1997. Colombo: Sri Lanka; 1997.

12. Khan M, Pillay T, Moodley JM, Connolly CA. Maternal mortality associated with tuberculosis-HIV-1 co-infection in Durban. South Afr AIDS. 2001;1863:15.

13. World Health Organization (WHO). Making pregnancy safer (MPS): a strategy for action. Safe Motherhood Newsletter. 2002.

14. Mekonnen Y. Patterns of Maternity Care Service Utilization in Southern Ethiopia: Evidence from a Community and Family Survey. Ethiop J Health Dev. 2003;17(1):27-33.

15. Wagstaff A, Claeson M. The millennium development goals for health rising to the challenges. Washington DC: The World Bank; 2004.

16. Unicef. Cross-sector indicators. [Available from <https://data.unicef.org/ resources/data_explorer/unicef_f/?ag=UNICEF\&d $\bar{d}=$ GLOBAL_DATAFLOW\&ver= $1.0 \& d q=S E N . M N C H$ SAB.\&startPeriod $=1970 \&$ endPeriod $=2020>$.

17. Yaya S, Bishwajit G. Predictors of institutional delivery service utilization among women of reproductive age in Gambia: a cross-sectional analysis. BMC Pregnancy Childbirth. 2020;20:187.

18. Adjiwanou V, LeGrand T. Gender inequality and the use of maternal healthcare services in rural sub-Saharan Africa. Health Place. 2014:29:67-78

19. Fekadu GA, Kassa GM, Berhe AK, Muche AA, Katiso NA. The effect of antenatal care on use of institutional delivery service and postnatal care in Ethiopia: a systematic review and meta-analysis. BMC Health Serv Res. 2018; 18:577. https://doi.org/10.1186/s12913-018-3370-9.

20. The Impact of Healthcare Insurance on the Utilization of Facility-Based Delivery for Childbirth in the Philippines. https://journals.plos.org/plosone/ article?id=10.1371/journal.pone.0167268. Accessed 17 Feb 2019.
21. Sialubanje C, Massar K, Hamer DH, Ruiter RAC. Personal and environmental predictors of the intention to use maternal healthcare services in Kalomo, Zambia. Health Educ Res. 2014;29:1028-40.

22. Ghose B, Feng D, Tang S, Yaya S, He Z, Udenigwe O, et al. Women's decision-making autonomy and utilization of maternal healthcare services: results from the Bangladesh demographic and health survey. BMJ Open. 2017;7:e017142.

23. Shah R, Rehfuess EA, Maskey MK, Fischer R, Bhandari PB, Delius M. Factors affecting institutional delivery in rural Chitwan district of Nepal: a community-based cross-sectional study. BMC Pregnancy Childbirth. 2015; 15:27.

24. Danforth EJ, Kruk ME, Rockers PC, Mbaruku G, Galea S. Household decisionmaking about delivery in health facilities: evidence from Tanzania. J Health Popul Nutr. 2009;27(5):696-703.

25. Feyissa TR, Genemo GA. Determinants of institutional delivery among childbearing age women in Western Ethiopia, 2013: unmatched case control study. PLoS One. 2014;9(5):1-7.

26. Zegeye K, Gebeyehu A, Melese T. The role of geographical access in the utilization of institutional delivery Service in Rural Jimma Horro District, Southwest Ethiopia. Prim Health Care. 2014;4:1.

27. Isa Al, Gani IOOJOJoO, Gynecology. Socio-demographic determinants of teenage pregnancy in the Niger Delta of Nigeria 2012;2(03):239.

28. UNICEF. Young people and family planning: teenage pregnancy. New York: UNICEF; 2008

29. Ritchwood TD, Ford H, DeCoster J, Sutton M, Lochman JEJC, review ys. Risky sexual behavior and substance use among adolescents: A meta-analysis. Child Youth Serv Rev. 2015;52:74-88.

30. Dulitha F, Nalika G, Upul S, Chrishantha WM, De Alwis SR, Hemantha S, et al. Risk factors for teenage pregnancies in Sri Lanka: perspective of a community based study. Health Sci J. 2013;7(4).

31. World Health Statistics. Maternal mortality ratio. 24, 2010

32. USAID/West Africa: Land Use and Land Cover Dynamics. The Republic of Senegal. [Available at <https://eros.usgs.gov/westafrica/country/repuplicsenegal >. Accessed on 06 May 2020].

33. Britannica. Republic of Senegal. [Available from <https://www.britannica. com/place/senegal $>$. Accessed on 02 May 2020].

34. World Bank. The World Bank in Senegal. [Available from <https://www. worldbank.org/en/country/senegal/overview>. Accessed on 06 May 2020].

35. Ministère de la Santé et de l'Action Sociale. Pyramide de Santé. [Available at <http://www.sante.gouv.sn/page-reader-content-details.php?.jpage=>NTg= \&jmenu= Mg= Accessed on 06 May 6, 2020].

36. Ministère de la Santé de l'Hygiène publique et de la Prévention du Sénégal. Politiques et normes de service de SR Partie 2. [Available from <http:// advancefami>lyplanning.org/resource/politiques-normes-et-protocoles-pnpen-sant\%C3\%A9-de-lareproduction-s\%C3\%A9n\%C3\%A9gal-fr Accessed on 06 May 6, 2020].

37. Agence Nationale de la Statistique et de la Démographie (ANSD) [Sénégal], et ICF. Senegal: Enquête Démographique et de Santé Continue (EDSContinue 2017). Rockville: ANSD et ICF. 2018. p. 1-454.

38. Yaya S, Bishwajit G, Shah V. Wealth, education and urban-rural inequality and maternal healthcare service usage in Malawi. BMJ Glob Health. 2016.

39. Bicego GTBJ. Maternal education and child survival: a comparative study of survey data from 17 countries. Soc Sci Med. 1993:36(9):1227.

40. Story WT, Burgard SA, Lori JR, Taleb F, Ali NA, Hoque DM. Husbands' involvement in delivery care utilization in rural Bangladesh: a qualitative study. BMC Pregnancy Childbirth. 2012;12:28.

41. Bishwajit G, Tang S, Yaya S, Ide S, Fu H, Wang M, et al. Factors associated with male involvement in reproductive care in Bangladesh. BMC Public Health [Internet]. 2017;17(1):3. Available from: https://doi.org/10.1186/ s12889-016-3915-y. [cited 2020 Dec 19].

42. Exavery A. Access to institutional delivery care and reasons for home delivery in three districts of Tanzania. Int J Equity Health. 2014; 13(48):11.

43. Esena RK, Sappor MM. Factors associated with the utilization of skilled delivery services in the Ga East Municipality of Ghana Part 2: barriers to skilled delivery. Int J Sci Technol Res. 2013;2(8):195-207.

44. Yaya S, Bishwajit G, Ekholuenetale M, Shah V. Awareness and utilization of community clinic services among women in rural areas in Bangladesh: a cross-sectional study. PLoS One. 2017;12:e0187303. 
45. Garedew GG, Zegeye B, Lemma G. Knowledge of obstetric danger signs and its associated factors among pregnant women in Angolela Tera District, Northern Ethiopia. BMC Res Notes. 2019;12:606.

46. Kipping R, Campbell RM, MacArthur G, Gunnell D, Hickman MJJPH. Multiple risk behaviour in adolescence. 2012;34(suppl_1):i1-2.

47. Laski LJ. Realising the health and wellbeing of adolescents. 2015;351:h4119.

48. Prakash R, Kumar A. Urban poverty and utilization of maternal and child health care services in India. J Biosoc Sci. 2013; 45:433-449. https://doi.org/ 10.1017/S0021932012000831 PMID: 23410254

49. Idris SH, Gwarzo UMD, Shehu AU. Determinants of place of delivery among women in a semi-urban settlement in Zaria, Northern Nigeria. Ann Afr Med. 2006;:68-72.

50. Abeje G, Azage M, Setegn T. Factors associated with institutional delivery service utilization among mothers in Bahir Dar City administration, Amhara region: a community based cross sectional study. Reprod Health. 2014;11(1):22.

51. Kidanu S, Degu G, Tiruye TY. Factors influencing institutional delivery service utilization in Dembecha district, Northwest Ethiopia: A community based cross sectional study. Reprod Health. 2017;14:98. https://doi.org/10.1186/ s12978-017-0359-5.

52. Shimeka AT, Mazengia FA, Meseret SW. Institutional delivery service utilization and associated factors among mothers who gave birth in the last 12 months in Sekela District, North West of Ethiopia. BMC Pregnancy Childbirth. 2012;12:74

53. Sharma SK, KC SP, Ghimire DR. Ethnic differentials of the impact of the family planning program on contraceptive use in Nepal. Demogr Res 2011; 25, 27:837-868.

54. Dahal GP, Padmadas SS, Hinde PRA. Fertility limiting behavior and contraceptive choice among men in Nepal. Int Fam Plan Perspect. 2008, 34(1):614.

55. Quan H, Fong A, Coster CD, Wang J, Musto R, Noseworthy TW, et al. Variation in health services utilization among ethnic populations. CMAJ. 2006:174(6):788

56. Mayberry RM, Mili F, Ofili E. Racial and ethnic differences in access to medical care. Med Care Res Rev. 2000;57(Suppl 1):108-45.

57. UNICEF. The state of the world's children 2011: adolescence an age of opportunity. New York: UNICEF; 2013.

58. Ayanaw Habitu Y, Yalew A, Azale Bisetegn TJJop. Prevalence and Factors Associated with Teenage Pregnancy, Northeast Ethiopia, 2017: A CrossSectional Study. 2018;2018.

59. Das JK, Salam RA, Thornburg KL, Prentice AM, Campisi S, Lassi ZS, et al. Nutrition in adolescents: physiology, metabolism, and nutritional needs. Ann N Y Acad Sci. 2017;1393(1):21-33.

60. WHO. The global strategy for women's, children's, and adolescents'health (2016-30). 2015.

\section{Publisher's Note}

Springer Nature remains neutral with regard to jurisdictional claims in published maps and institutional affiliations.

Ready to submit your research? Choose BMC and benefit from:

- fast, convenient online submission

- thorough peer review by experienced researchers in your field

- rapid publication on acceptance

- support for research data, including large and complex data types

- gold Open Access which fosters wider collaboration and increased citations

- maximum visibility for your research: over $100 \mathrm{M}$ website views per year

At $\mathrm{BMC}$, research is always in progress.

Learn more biomedcentral.com/submissions 